\title{
Articles
}

\section{Does France's Two-Ballot Presidential Election System Alter Candidates' Policy Strategies? A Spatial Analysis of Office-Seeking Candidates in the 1988 Presidential Election ${ }^{1}$}

\author{
James Adams ${ }^{\mathrm{a}}$, Samuel Merrill III $^{\mathrm{b}}$ and Bernard Grofman ${ }^{\mathrm{c}}$ \\ ${ }^{a}$ Department of Political Science, University of California, Santa Barbara, Santa Barbara, CA \\ 93106-9420, USA; \\ ${ }^{\mathrm{b}}$ Department of Mathematics and Computer Science, Wilkes University, Wilkes-Barre, PA 18766, \\ USA; \\ ${ }^{\mathrm{c}}$ School of Social Sciences, University of California, Irvine, 3151 Social Science Plaza, Irvine, CA \\ 92697-5100, USA. \\ E-mail: adams@polsci.ucsb.edu
}

With rare exceptions, spatial models of candidate strategies under plurality rule have analyzed single-stage plurality elections. In this paper, we explore whether the two-stage French presidential election system plausibly changes the major candidates' policy incentives, compared to what their incentives would be in a single-stage plurality contest. We report the results of counterfactual simulations on survey data from the 1988 presidential election, which suggest that the officeseeking candidates' strategies would be similar under two-stage and single-stage plurality rules.

French Politics (2005) 3, 98-123. doi:10.1057/palgrave.fp.8200074

Keywords: spatial modeling; Nash equilibrium; presidential elections; behavioral research; French politics

\section{Introduction}

With rare exceptions, spatial models of candidate strategies under the plurality voting system have analyzed single-stage plurality elections, that is, elections in which the winning candidate is the one who receives the most votes in a single round of voting. ${ }^{2}$ Among advanced industrial societies, France is a notable example of a country that features a two-stage plurality process for selecting representatives to its national legislature (The National Assembly) as well as to the presidency. ${ }^{3}$ In this paper, we explore the following question, in the context of the 1988 French Presidential election: Does the two-stage process for electing the French president change the policy strategies that competitive, office-seeking candidates would plausibly pursue, compared with the strategies 
they would pursue if the winning candidate were selected in a single-stage plurality process?

In this paper, we argue that the surprising answer to the above question is no. Specifically, we report analyses of survey data drawn from the 1988 French presidential election, which provides estimates of the electoral impacts of the candidates' policy proposals. We then elaborate a simple way that the competitive presidential candidates in this election - the Socialist Francois Mitterrand, the Gaullist Jacques Chirac, and the UDF candidate Raymond Barre - might have used our computations in formulating their policy strategies. This approach takes as its starting point our survey data analyses, in which we compute each candidate's expected vote share - in both the first round and second rounds of voting - as a function of the candidate's Left-Right position. This approach also allows us to analyze counterfactual scenarios in which the winner was selected in a one-stage plurality process.

Our analysis leads us to the following conclusion: that for both the actual two-stage election process, and given plausible assumptions about how a one-stage election process would have unfolded - namely, that the major left-wing parties (the Socialists and Communist parties) and the major right-wing parties (the UDF and the RPR) would have each united behind a single candidate to contest the election - office-seeking candidates would have been motivated to present relatively centrist policies, for both two- and one-stage plurality elections. Furthermore, this conclusion on the candidates' policy incentives in a hypothetical one-stage selection process persists regardless of whether the extremist National Front candidate Le Pen would have chosen to contest a single-stage election, and the conclusion is also robust to alternative assumptions about whether, in a one-stage plurality election, the mainstream right-wing parties would have coalesced behind Barre or Chirac. We therefore conclude that, in the context of French politics in 1988, the two-stage feature of the presidential selection process probably did not much affect the competitive candidates' policy strategies, compared with what could have been expected in a single-stage election process.

This paper is organized as follows. The next section discusses the 1988 French presidential election, both in terms of the actual two-stage contest that took place, and in terms of how the election might have unfolded had the winner been determined in a single stage. The subsequent section we analyze survey data from this election, and we use these analyses to compute the effects of candidate positioning upon their expected vote shares. The next section presents our computations on the competitive candidates' equilibrium positions, for alternative one- and two-stage election scenarios. Finally, the conclusions are given. 


\section{Counterfactual Simulations and the 1988 French Presidential Election}

\section{The context of the election}

French presidential elections feature two stages, with the two top finishers in the first round of voting advancing to a runoff election held 2 weeks later, and the winner determined by direct popular vote. The first round of the 1988 election featured five major candidates: the Communist Party's candidate Andre Lajoinie; the Socialist Francois Mitterrand, who was the incumbent President; Raymond Barre, the candidate of the center-right Union for French Democracy (UDF); Jacques Chirac, the candidate of the right-wing Rally for the Republic (RPR); and Jean-Marie Le Pen, the candidate of the far right, anti-immigration National Front. ${ }^{4}$ Each of these candidates won over $8 \%$ of the first-round vote, and collectively they received over $90 \%$ of the vote. As reported in Table 1, Mitterrand and Chirac were the two top vote-getters at the first ballot, with Mitterrand outdistancing the rest of the field with a $34 \%$ vote share, and Chirac, with $19.8 \%$ of the vote, narrowly outdistancing Barre (16.5\%) and Le Pen (14.6\%). In the subsequent runoff election Mitterrand defeated Chirac 54-46\%, thereby winning a second presidential term.

\section{Office-seeking strategies}

Candidate strategies for the actual two-stage election

In an earlier paper on the 1988 French presidential election (Adams and Merrill, 2000), we analyzed the candidates' policy strategies using the assumption that all five of the major party candidates selected their policy programmes with an eye towards maximizing their first-round vote. Here, in

Table 1 French presidential election results, 1988

\begin{tabular}{lcc}
\hline & First ballot $^{\mathrm{a}}$ (April 24, 1988) & Second ballot (May 8, 1988) \\
\hline Francois Mitterrand & $34.0 \%$ & $54.0 \%$ \\
Jacques Chirac & 19.8 & 46.0 \\
Raymond Barre & 16.5 & \\
Jean-Marie Le Pen & 14.6 & \\
Andre Lajoinie & 6.9 & \\
Antione Waechter & 3.8 & \\
Pierre Juquin & 2.1 & 84.6 \\
Arlette Laguiller & 2.0 & \\
Pierre Boussel & 0.3 & \\
Voter Turnout & 82.0 & \\
\hline
\end{tabular}

${ }^{a}$ Candidate vote percentages for both rounds are calculated as a percentage of valid votes cast. 
exploring the candidates' office-seeking strategies for the two-stage selection process, we modify this assumption to account for two factors: first, that the competitive candidates were plausibly concerned with both rounds of voting; second, that not all of the candidates in the 1988 election were competitive, and that these noncompetitive candidates plausibly selected their policy positions based on alternative criteria. With respect to this latter point, we note that Lajoinie and Le Pen, the nominees of the small, extremist Communist and National Front parties, had no realistic chance of being elected, regardless of the policy positions they presented. ${ }^{5}$ We shall therefore confine our exploration of office-seeking motivations to Mitterrand, Barre, and Chirac, the three competitive candidates, while assuming that Lajoinie and Le Pen selected their platforms on the basis of expressive motivations, that is their desire to articulate their sincere policy preferences: ${ }^{6}$

Assumption 1 on two-stage elections. Lajoinie and Le Pen selected their policy positions on the basis of their sincere preferences, which were independent of the policy positions presented by the competitive candidates Mitterrand, Barre, and Chirac.

With respect to Mitterrand, Barre, and Chirac, the analysis of these competitive candidates' office-seeking strategies revolves around how they plausibly weighted electoral support in the first round of voting against support at the decisive second ballot. To begin with, we assume that these candidates were constrained to present a single, consistent set of policy positions over the two rounds of voting - an assumption that appears reasonable given that these two stages were separated by only 2 weeks, so that any attempt by a candidate to dramatically alter his policy image between the first and second rounds would likely expose him to charges of flip-flopping and political opportunism. In the case of Mitterrand, who was expected to advance easily to the second round - an expectation that proved well-founded, as Mitterrand polled nearly twice as many first-round votes as his nearest competitor (see Table 1) — it appears plausible that Mitterrand weighted second-round support more heavily than support in the first round. The cases of Barre and Chirac are more complicated. These two candidates were locked in a close contest for the runner-up spot at round one, so that they surely weighted their first-round support heavily, relative to their electoral support at round two (should they qualify for the runoff). More specifically, Barre and Chirac's calculations relative to the first ballot plausibly revolved around their expected vote margins relative to each other - rather than simply maximizing their respective expected votes - since only one of them was likely to advance to the second round. These considerations motivate our second assumption, concerning Barre's and Chirac's office-seeking strategies in the first round of voting: 
Assumption 2 on two-stage elections. Barre and Chirac's emphasis in the first round was on maximizing their expected support relative to each other, while Mitterrand's first-round emphasis was on maximizing his vote share. ${ }^{7}$

As denoted in Eqs. (2) and (3) below, the above assumption implies that Barre and Chirac were each concerned with the difference between their expected first-round vote and the other's first-round vote, rather than focusing exclusively on their own vote. This implies, for instance, that Barre would prefer an outcome in which he received $20 \%$ of the first-round vote while Chirac received 19\%, compared to an outcome in which Barre received $21 \%$ of the vote but Chirac received $22 \%$.

Finally, we consider how the competitive candidates strategized about the effects of their policy positioning on the outcome of the second round of voting. It seems reasonable to assume that Chirac and Barre based their policy strategies on the supposition that, in the event they advanced to the runoff, their second-round opponent would be Mitterrand. Mitterrand faced a more complicated strategic calculus, given the uncertainty surrounding the identity of his second-round opponent. Accordingly, we analyzed Mitterrand's policy strategies for two alternative scenarios: one in which Mitterrand plotted his strategy in the expectation that he would face Chirac in the runoff election, and the other in which he expected to face Barre. Since we found that both scenarios supported identical substantive conclusions, here we will focus primarily on the situation in which Mitterrand assumed he would face Chirac (however, footnote ${ }^{19}$ below reports results for simulations in which we assumed that Mitterrand expected to face Barre in the runoff):

Assumption 3 on two-stage elections. Barre and Chirac's emphasis with respect to the second ballot revolved around maximizing their expected votes vis-à-vis Mitterrand, while Mitterrand selected his strategy under the assumption that his second round opponent would be Chirac.

Finally, in analyzing the competitive candidates' strategies for two-round elections, we must specify the relative weights that the candidates attached to the outcomes of the first and second rounds. Let $w_{1}$ be the weight that a given candidate attached to round 1 , and $\left[1-w_{1}\right]$ the weight the candidates attached to round 2 . We assume that $w_{1}$ is the same for each competitive candidate. ${ }^{8}$ Then we specify the competitive candidates' utility functions as follows, where $U(M), U(B)$, and $U(C)$ represent the utilities for Mitterrand, Barre, and Chirac, respectively:

$$
\begin{gathered}
U(M)=w_{1} \times \mathrm{EV}_{1}(M)+\left(1-w_{1}\right) \times \mathrm{EV}_{2}\left(M_{\mathrm{C}}\right) \\
U(B)=w_{1} \times\left[\mathrm{EV}_{1}(B)-\mathrm{EV}_{1}(C)\right]+\left(1-w_{1}\right) \times \mathrm{EV}_{2}\left(B_{\mathrm{M}}\right) \\
U(C)=w_{1} \times\left[\operatorname{EV}_{1}(C)-\mathrm{EV}_{1}(B)\right]+\left(1-w_{1}\right) \times \mathrm{EV}_{2}\left(C_{\mathrm{M}}\right)
\end{gathered}
$$


where, $\operatorname{EV}_{1}(M)$ is Mitterrand's expected first-round vote, $\operatorname{EV}_{2}\left(M_{\mathrm{C}}\right)$ is Mitterrand's expected second-round vote, assuming his opponent is Chirac, $\mathrm{EV}_{1}(B)$ is Barre's expected first-round vote, $\mathrm{EV}_{2}\left(B_{\mathrm{M}}\right)$ is Barre's expected second-round vote, assuming his opponent is Mitterrand, $\mathrm{EV}_{1}(C)$ is Chirac's expected first-round vote and $\mathrm{EV}_{2}\left(C_{\mathrm{M}}\right)$ is Chirac's expected second-round vote, assuming his opponent is Mitterrand.

Below we explore the candidates' strategies, as delineated in Eqs. (1)-(3), for alternative values of the weighting parameter $w_{1}$, which represents the emphasis the candidates' placed upon their first-round votes relative to the second round. ${ }^{9}$

\section{Candidate strategies for a hypothetical one-stage election}

In comparing the candidates' office-seeking incentives for the actual two-stage 1988 French presidential election, with the candidates' plausible incentives under a one-round presidential election system, we confront the counterfactual question: What are plausible assumptions about how the presidential election would have unfolded, had there been a single round of voting? This question is impossible to answer definitively, for if French presidential elections were oneround contests - and if moreover parliamentary elections were also one round - then the party system would likely have developed quite differently. ${ }^{10}$ In particular, it is plausible that one-round elections would have motivated the political elites of the Communist and Socialist parties to merge into a single major left-wing party in order to avoid splitting the left-wing vote, with the politicians of the mainstream right parties similarly merging to form a single party (see Duverger, 1954). Indeed, we note that the strategy of coalescing behind a single candidate at the decisive ballot is already in operation under the current two-ballot system for parliamentary elections, for which the four mainstream political parties form pre-election electoral pacts such that the Communist-Socialist bloc and the UDF-RPR bloc agree in advance to present a single left-wing (right-wing) candidate at the second round of voting. ${ }^{11}$

While acknowledging that we cannot foresee how the counterfactual scenario involving a one-round presidential election would have unfolded, the existence of the parliamentary electoral alliances described above provides some basis for prediction. We therefore employ the following assumption about how the 1988 French presidential election would have unfolded, had it been a one-round plurality election:

Assumption 1 on one-round elections. Had the 1988 French presidential election been a one-round plurality contest, the two major left-wing parties (the Communists and the Socialists) and the two major right-wing parties (the $U D F$ and the RPR) would have each united behind a single candidate. 
In the case of the left, it seems certain that their candidate of choice in a oneround election would have been Francois Mitterrand, for not only was he the incumbent President but his political support far exceeded that of the Communist party's candidate Andre Lajoinie (see Table 1):

Assumption 2 on one-round elections. In a one-round French presidential election contest, Mitterrand would have been the single candidate fielded by the major left-wing parties.

The case of the major right-wing parties is less clear, since Chirac, the RPR's candidate, and Barre, the UDF's candidate, had approximately equal levels of support (see Table 1), so that it was unclear which of them would be a stronger representative for the mainstream right. Accordingly, we will explore two different scenarios, one in which the mainstream right united behind Barre, and another in which they united behind Chirac.

Finally, we note that the strategic decisions that the far right National Front, and their leader, Jean-Marie Le Pen, would have made in the event of a oneround presidential contest are difficult to determine. On the one hand the National Front and Le Pen would have had strategic motivations not to contest a one-round presidential election, given that Le Pen had little chance of being elected, and that his candidacy would surely have siphoned off support from the mainstream right-wing candidate, whom the National Front's supporters plausibly preferred to Mitterrand. On the other hand, Le Pen and the National Front would have had several countervailing motivations to actively contest a single-stage election. These include: the fact that Le Pen's candidacy would plausibly motivate the mainstream Right's candidate to present a more conservative platform, which would prove more attractive to the National Front in the event this right-wing candidate won the election; that in contesting the presidential election the National Front could demonstrate its importance in French politics; that Le Pen and the National Front might plausibly have derived an expressive benefit from articulating the National Front's far right, anti-immigration philosophy during the election campaign. ${ }^{12}$

Given the conflicting considerations discussed above, we will explore the candidates' office-seeking incentives for two alternative one-round scenarios, one in which Le Pen was assumed to contest the election, and the other in which he did not. However, we will employ the simplifying assumption that in the event that Le Pen had contested a one-round plurality election, he would have presented the same policy positions that he was actually observed to present in the 1988 French presidential election. We believe this simplifying assumption is plausible, because the central factors that would have motivated Le Pen's decision to contest a one-round election - the expressive motivation to articulate the National Front's extreme policy positions, and the desire to demonstrate the National Front's importance in French politics — were 
compatible with the decision to articulate the National Front's sincere policy stances. Further support for this assumption is provided by Adams et al. (2004b), who report empirical analyses suggesting that extreme nationalist parties (such as the National Front) do not adjust their policy programmes in response to shifts in public opinion. Accordingly, we will investigate the following four one-round election scenarios:

Scenario 1: A Mitterrand-Barre contest, in which both candidates were assumed to choose ideological positions that maximized their expected vote shares.

Scenario 2: A Mitterrand-Chirac contest, in which both candidates were assumed to choose ideological positions that maximized their expected vote shares.

Scenario 3: A Mitterrand-Barre-Le Pen contest, in which Mitterrand and Barre were assumed to choose ideological positions that maximized their vote shares relative to each other, ${ }^{13}$ while Le Pen presented the positions that reflected his sincere policy beliefs.

Scenario 4: A Mitterrand-Chirac-Le Pen contest, in which Mitterrand and Chirac were assumed to choose ideological positions that maximized their vote shares relative to each other, while Le Pen presented the positions that reflected his sincere policy beliefs.

\section{Candidate Positioning and Voting Patterns in the 1988 French Presidential Election}

In Pierce's 1988 French Presidential Election Survey, 1013 respondents were asked to place both themselves and the five major presidential candidates on four different seven-point scales: Left-Right, church schools, public sector, and immigration. The Left-Right scale runs from 1 (extreme left) to 7 (extreme right); on church schools, the scale is from 1 ('the state should not subsidize church schools') to 7 ('the state should increase subsidies for church schools'); on the public sector, the scale is from 1 ('supports a large public sector') to 7 ('the role of the state in the economy should be reduced'); the immigration scale runs from 1 ('we should integrate immigrants into French society) to 7 ('immigrants should return to their native country'). ${ }^{14}$

Table 2 shows the respondents' mean positions, as well as their mean candidate placements, for the subsample of 748 respondents who reported voting for one of the five major candidates on the first ballot, and who could place themselves on the Left-Right dimension. Note first that the French public appears centrist (on average) on each dimension, but that the candidates were perceived as taking quite divergent positions, with the Communist Lajoinie placed on the far left of each dimension, and Le Pen placed at the extreme right 
Table 2 Candidates' ideological and policy positions on a 1-7 scale, as perceived by the French electorate, 1988

\begin{tabular}{lcccc}
\hline & \multicolumn{4}{c}{$n=748$} \\
\cline { 2 - 5 } & Left-Right & Immigration & Public Sector & Church Schools \\
\hline Mean voter position & 3.97 & 3.76 & 3.88 & 4.66 \\
Lajoinie & 1.90 & 2.29 & 1.93 & 2.34 \\
Mitterrand & 3.09 & 2.43 & 2.89 & 3.57 \\
Barre & 4.81 & 4.07 & 5.06 & 5.08 \\
Chirac & 5.55 & 4.54 & 5.75 & 5.34 \\
Le Pen & 6.57 & 6.80 & 5.55 & 5.16 \\
\hline
\end{tabular}

Source: 1988 French Presidential Election Study.

of the Left-Right and the immigration scales. Mitterrand was viewed as centerleft along each dimension, while Barre and Chirac were seen as center-right. These respondent placements accord well with experts' placements of the French parties' positions (see Huber and Inglehart, 1995, 97), thereby supporting Pierce's conclusion (1995, 67-73) that French voters had sharply edged perceptions of the candidates' policy images.

Our central interest is whether the candidates' policy strategies would have been very different under a one-round election system, compared with the actual two-round system that was in effect. To address this question we develop an empirical, random-utility model of voter choice that incorporates policy factors relating voters and candidates, nonpolicy factors idiosyncratic to the voters, and voter-specific random components unknown to the candidates. This model — as well as estimation of its parameters from the 1988 French Presidential Election Survey - is described in detail in Appendix A.

\section{Exploring counterfactual scenarios: assumptions about voting behavior in the runoff election, and in a one-round plurality election}

While the statistical analyses reported in Appendix A provide a basis for understanding the French electorate's decision rules in the first round of voting in the two-stage 1988 presidential election, we confront two counterfactual questions on voting behavior, in order to analyze how office-seeking candidates' strategies would likely have differed between one-round and tworound plurality elections. These questions are: On what basis would French voters have evaluated the candidates in a one-round plurality election along the lines of the contests delineated in scenarios 1-4 above, that is, a one-round contest that pitted Mitterrand against either Barre or Chirac (and with Le Pen possibly contesting the election as well)? Second, with respect to the actual 
two-stage plurality election, on what basis would French voters have plausibly evaluated the candidates in the second round of voting?

With respect to the second question, our previous analyses of first- and second-round voting in the 1988 French presidential election (see Adams et al., 2004b, Chapters 5 and 12) suggest that voters' decision rules in the MitterrandChirac runoff election had a similar basis to their decision rules in the first round of voting, with one crucial difference: namely, that voters who identified with either of the major left-wing parties (the Communists and the Socialists) gave a nonpolicy-related advantage to the leftist candidate Mitterrand in round 2, and that, similarly, partisans of both the UDF and the RPR displayed nonpolicy-related loyalties to the right-wing candidate Chirac. That is, in the runoff election the partisans of both major left-wing parties behaved as if they identified with Mitterrand's Socialist party, while the partisans of both mainstream right-wing parties behaved as if they were partisans of Chirac's RPR. This finding is understandable, given that the left- and right-wing blocs regularly oppose each other in parliamentary elections. ${ }^{15}$ Accordingly, in our subsequent computations we employ the following assumptions about the candidates' beliefs on how the French electorate would behave, under alternative election scenarios:

Assumptions on voting in the runoff election. We assume that the parameters reported in Table A1 (part a) in Appendix A, which were estimated based upon survey respondents' reported first-round vote choices, apply equally to their choices in a Mitterrand-Chirac or a Mitterrand-Barre runoff election, with the following exception: namely, that partisans of both major left-wing parties would behave as if they were partisans of Mitterrand's Socialist party, while partisans of the UDF and the RPR would behave as if they identified with the right-wing candidate's party.

Assumptions on voting in a one-round election. We assume that the parameters reported in Table A1 (part a) in Appendix A would apply equally to voters' choices in a one-round plurality election featuring Mitterrand vs either Barre or Chirac (and also possibly featuring Le Pen), but that, as discussed above, partisans of both major left-wing parties would behave as if they were partisans of Mitterrand's Socialist party, while partisans of the UDF and the RPR would behave as if they identified with the right-wing candidate's party.

We employ an additional assumption on voting in single-stage, threecandidate elections involving Mitterrand-Barre-Le Pen or Mitterrand-ChiracLe Pen: namely, that in such scenarios Le Pen's supporters would have voted sincerely, as opposed to strategically deserting Le Pen in favor of one of the major candidates. We assume sincere voting because empirical research by Givens (2005) on three-candidate, second-round elections to the National 
Assembly suggests that most National Front partisans did not strategically desert their party's candidate at the decisive ballot. This implies that our assumption of sincere voting by Le Pen supporters is realistic. Furthermore, we note that to the extent that Le Pen's supporters would have strategically deserted their candidate in a single-stage, three-candidate election, the election would be effectively reduced to a two-candidate contest between Mitterrand and one of the major right-wing candidates. Thus our simulations on the pure two-candidate elections between Mitterrand-Barre or Mitterrand-Chirac provide reasonable estimates of what these candidates' strategies would be if Le Pen had contested the race but his supporters had voted strategically.

\section{Candidate Policy Strategies: A Simulation Approach}

\section{Effects of candidate policy movement on the first-round presidential vote}

Our particular interest is how, in the 1988 French presidential election, the policy incentives for the competitive candidates Mitterrand, Barre, and Chirac would have differed in a one-round contest compared with the actual two-stage contest that took place. We use Eq. (A3) (see Appendix A) to calculate the electoral effects of changes in the candidates' Left-Right positions. Specifically, we simulated the effect of each candidate moving across the Left-Right dimension, holding the positions of the other four candidates unchanged. At each position, we computed the probability of each respondent voting for each of the candidates. These probabilities were recomputed with everything else held fixed except the position of a single candidate, whose policy position was adjusted from 1 to 7 in increments of 0.05 . In these exercises we placed no restrictions on candidate positioning, so that we even considered outcomes in which the Socialist candidate Mitterrand, for example, took positions on the right. ${ }^{16}$ We harbor no illusions that real world candidates can manipulate their policy images in this fashion, and in fact we suspect that had any of the French candidates taken positions dramatically at variance with their previous policy statements, such behavior would have been seen by the electorate as opportunistic and punished accordingly. However, since we find that the major candidates' policy optima resemble their actual (perceived) positions even given the unrealistic assumption of costless spatial mobility, this conclusion would certainly hold if we specified a penalty for dramatic policy shifts. In this spirit we proceed.

Figures 1(a-c) show the predicted first-round votes for Mitterrand (Figure 1a), Barre (Figure 1b), and Chirac (Figure 1c), as a function of the candidates' positions on the Left-Right dimension. Also marked are the candidates' vote-maximizing Left-Right positions, along with their actual (perceived) position on this dimension. In addition, we have also indicated the 
positions for Barre and Chirac that would have maximized each candidate's expected margin $v s$ the other; ${ }^{17}$ we provide this information because, as discussed in the section on Counterfactual Simulations and the 1988 French Presidential Election, we assume that to the extent that Barre and Chirac selected their policy strategies with an eye towards the first round of voting, their goal was to finish ahead of their right-wing rival rather than to maximize their first-round vote share. The most striking observation is that each of the competitive candidates located quite near his computed optimal position for the first round, with each candidate locating less than 0.7 units away from his vote- or margin-maximizing position along the 1-7 Left-Right scale.

\section{Candidate equilibria in two-round versions of the French presidential election}

Although the policy optima presented in Figure 1 are suggestive, note, first, that these optima are based entirely on the first round of voting, and, second, that each candidate's first-round optimum was computed using the assumption that all rival candidates were located at their actual (perceived) positions. The former assumption ignores the fact that the candidates plausibly weighed the impacts of their policy strategies upon both their first- and their second-round votes, as delineated in the candidate utility functions represented by Eqs. (1)(3) in the section Counterfactual Simulations and the 1988 French Presidential Election. The latter assumption is problematic because the candidates could be expected to react to each other, so that they might eventually converge to a Nash equilibrium, that is, a configuration of policy strategies such that no candidate would have an incentive to shift his position, given the positioning of the rival candidates.

Accordingly, we computed the equilibrium positions for the competitive candidates Mitterrand, Barre, and Chirac, using the algorithm presented in Merrill and Adams (2001). As discussed in the section Counterfactual Simulations and the 1988 French Presidential Election, for these computations we fixed the noncompetitive candidates Le Pen and Lajoinie at their actual (perceived) positions, that is, we assumed that these candidates did not react to their competitors' policy strategies, but instead articulated their sincere policy preferences. We computed the competitive candidates' Left-Right equilibrium positions while fixing all of the candidates at their actual (perceived) positions along the policy scales for immigration, church schools, and the public sector. ${ }^{18}$

Table 3 reports the candidates' Nash equilibrium positions, for alternative assumptions about the relative weights that they attached to the first-round vote (represented by the parameter $w_{1}$ ) compared to the second-round vote (represented by the parameter $\left[1-w_{1}\right]$ ). For the unrealistic scenario in which the candidates cared only about the first round of voting $\left(w_{1}=1\right)$, the computed 
-if. James Adams et al.

France's Two-Ballot Presidential Election System

110
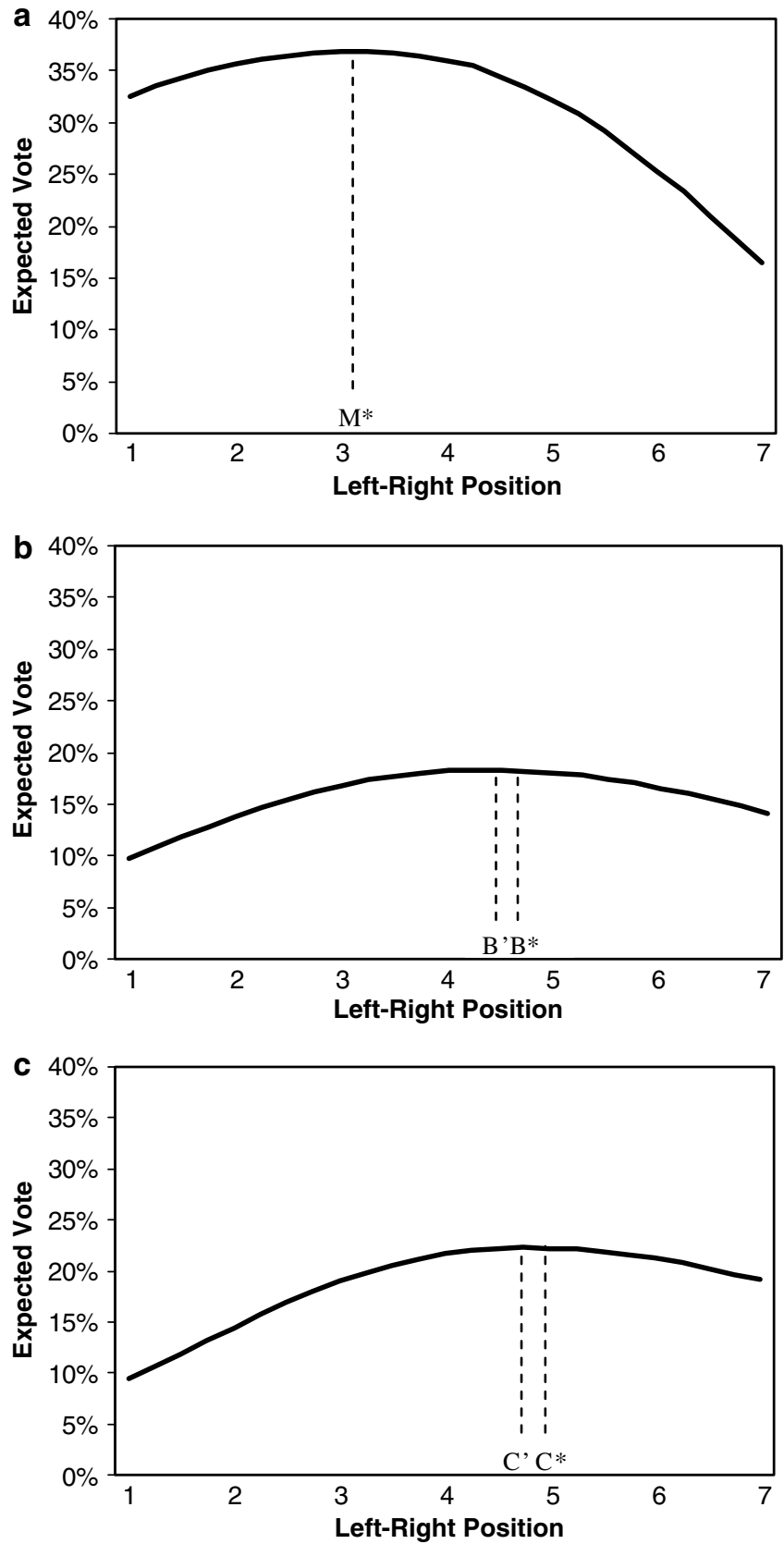
Table 3 French presidential candidates' equilibrium Left-Right positions, for two-stage plurality elections

\begin{tabular}{lccc}
\hline Candidate's weight $w_{1}$ for the first round of voting & Mitterrand & Barre & Chirac \\
\hline$w_{1}=1.00$ (1st round emphasis) & 3.09 & 4.69 & 4.93 \\
$w_{1}=0.75$ & 3.27 & 4.47 & 4.71 \\
$w_{1}=0.50$ & 3.47 & 4.27 & 4.47 \\
$w_{1}=0.25$ & 3.71 & 4.07 & 4.21 \\
$w_{1}=0.00$ (2nd round emphasis) & 3.93 & 3.93 & 3.93 \\
Candidate's actual position & 3.09 & 4.81 & 5.55 \\
\hline
\end{tabular}

Notes: For these computations the competitive candidates Mitterrand, Barre, and Chirac were fixed at their actual (perceived) positions along the policy scales for immigration, Church Schools, and Public Sector, while the candidates Lajoinie and Le Pen were fixed at their actual (perceived) positions along these policy scales and the Left-Right scale. The utility functions for the competitive candidates are given by Eqs. (1)-(3) in the text. For Mitterrand, the weight $w_{1}$ represents the tradeoff between Mitterand's expected first-round vote and his expected second-round vote in a runoff vs Chirac. For Barre and Chirac, the weight $w_{1}$ represents the trade-off between the candidate's expected first-round vote margin $v s$ his mainstream right-wing competitor, and the candidate's expected second-round vote in a runoff $v s$ Mitterrand.

Figure 1 (a) Mitterrand's expected vote as a function of his ideological position, for the first round of the 1988 French presidential election. Notes: The figure presents Mitterrand's expected firstround vote as a function of his (mean perceived) Left-Right position, with the rival candidates fixed at their actual Left-Right positions, and with each candidate fixed at his actual position along the additional policy dimensions included in the empirical voting specification. The label ' $\mathrm{M}^{*}$ ' represents Mitterrand's computed vote-maximizing position. Mitterrand's expected vote shares for alternative Left-Right positions were computed using the estimated parameters for the voting specification reported in Table A1 (part a). (b) Barre's expected vote as a function of his ideological position, for the first round of the 1988 French presidential election. Notes: The figure presents Barre's expected first-round vote as a function of his (mean perceived) Left-Right position, with the rival candidates fixed at their actual Left-Right positions, and with each candidate fixed at his actual position along the additional policy dimensions included in the empirical voting specification. The label ' $\mathrm{B}^{*}$ ' represents Barre's computed vote-maximizing position, while the label ' $\mathrm{B}^{\prime}$ ' represents Barre's computed margin-maximizing position vis-à-vis Chirac. Barre's expected vote shares for alternative Left-Right positions were computed using the estimated parameters for the voting specification reported in Table A1 (part a). (c) Chirac's expected vote as a function of his ideological position, for the first round of the 1988 French presidential election. Notes: The figure presents Chirac's expected first-round vote as a function of his (mean perceived) Left-Right position, with the rival candidates fixed at their actual Left-Right positions, and with each candidate fixed at his actual position along the additional policy dimensions included in the empirical voting specification. The label ' $\mathrm{C}$ ') represents Chirac's computed vote-maximizing position, while the label ' $\mathrm{C}$ ' represents Chirac's computed margin-maximizing position vis- $\dot{a}$-vis Barre. Chirac's expected vote shares for alternative Left-Right positions were computed using the estimated parameters for the voting specification reported in Table Al (part a). 
Nash equilibrium finds the candidates adopting moderately dispersed positions, with Mitterrand locating at 3.09 along the 1-7 Left-Right scale, and Barre and Chirac located at the center-right positions 4.69 and 4.97, respectively. This equilibrium configuration resembles the actual configuration of the candidates' (mean perceived) policy strategies, which was 3.09 for Mitterrand, 4.81 for Barre, and 5.55 for Chirac (see Table 3). However, for more realistic scenarios in which the candidates emphasized both rounds of voting (i.e., when $w_{1}$ was set at a value between zero and one), the candidates' equilibrium positions are all relatively centrist. For instance, for the scenario in which the candidates attached equal weights to the first and second rounds of the election $\left(w_{1}=0.5\right)$, the equilibrium configuration locates Mitterrand at 3.37, Barre at 4.27, and Chirac at 4.47. Finally, we find that had the candidates been completely concerned with the runoff election $\left(w_{1}=0\right)$, they would have had incentives to converge to identical, centrist positions along the Left-Right scale. This result is consistent with previous spatial studies of two-candidate competition for a voting model based on the behavioralists' multivariate specification (see Erikson and Romero, 1990). ${ }^{19}$

Our finding, that the candidates would have incentives to moderate when they considered the effects of their policies upon their prospects in the twocandidate runoff election, is driven by the Downsian logic that two-candidate elections motivate policy moderation from office-seeking candidates. In the case of our simulations on the 1988 French presidential election data we find that this centripetal incentive is sufficiently strong that, the centrifugal incentives relating to the first round of voting notwithstanding, this two-stage election process would motivate relatively centrist strategies by office-seeking candidates.

\section{Candidate equilibria for one-round versions of the presidential election}

Next, we analyzed the candidates' policy motivations for the four one-round election scenarios delineated in the section Counterfactual Simulations and the 1988 French Presidential Election. These include: a three-candidate scenario involving Mitterrand, Barre, and Le Pen; a three-candidate scenario involving Mitterrand, Chirac, and Le Pen; a two-candidate contest between Mitterrand and Barre; a two-candidate contest involving Mitterrand and Chirac. As discussed in the second section, in our computations we assumed that, had Le Pen contested a one-round version of the election, he would have presented the same policy positions that he actually advocated in the 1988 two-stage presidential election. We also assumed that in a three-candidate election involving Le Pen, the two competitive candidates (i.e. Mitterrand and Barre/Chirac) would have each maximized 
Table 4 French presidential candidates' equilibrium Left-Right positions, for alternative one-stage plurality election scenarios

\begin{tabular}{lccc}
\hline & Mitterrand & Barre & Chirac \\
\hline Mitterrand-Barre & 3.93 & 3.93 & - \\
Mitterrand-Barre-Le Pen & 3.64 & 4.24 & - \\
Mitterrand-Chirac & 3.93 & - & 3.93 \\
Mitterrand-Chirac-Le Pen & 3.68 & - & 4.26 \\
Candidate's actual position & 3.09 & 4.81 & 5.55 \\
\hline
\end{tabular}

Notes: For these computations the competitive candidates Mitterrand, Barre, and Chirac were fixed at their actual (perceived) positions along the policy scales for immigration, Church Schools, and Public Sector, and their equilibrium Left-Right positions were computed on this basis. For the three-candidate election scenarios, Le Pen was located at his actual (perceived) positions along these policy scales and the Left-Right scale. For the three-candidate scenarios the two competitive candidates were assumed to maximize their expected vote margins $v s$ each other, while in the twocandidate scenarios the candidates were assumed to maximize their expected vote shares.

his expected margin vis-à-vis the other competitive candidate contesting the race.

The candidates' computed equilibrium positions for alternative one-round scenarios are reported in Table 4. We again find, as expected, that in the hypothetical one-round contests pitting Mitterrand against either Barre or Chirac, both candidates would have had office-seeking incentives to converge to identical, centrist positions.

The presence of Le Pen in the race would have given the two competitive candidates incentives to diverge moderately from each other, with the major right-wing candidate's optimal position shifting modestly to the right compared to the pure two-candidate scenario, and Mitterrand's optimal position shifting modestly to the left. ${ }^{20}$ The degree of policy divergence between the major candidates' policy optima with Le Pen in the race - about 0.6 policy units along the 1-7 Left-Right scale - is roughly comparable to what we estimated for the two-stage election scenarios, when the candidates were assumed to attach equal importance to both rounds of voting.

\section{Conclusion}

We have analyzed the policy incentives for office-seeking candidates in the 1988 French presidential election, both under the actual two-ballot plurality structure that was used to select the president, and for alternative one-ballot plurality scenarios. Our chief aim has been to estimate whether a shift to a oneballot plurality process would have significantly changed the candidates' policy 
incentives. We find that to answer this question we must confront several preliminary questions, including: Given the actual two-stage plurality contest, how did the competitive candidates plausibly trade off support in the first round of voting against support in the runoff election?, and, had the 1988 election been a one-stage contest, what set of candidates would have contested the election?

Given that there are no obvious answers to the above questions, we have analyzed the policy incentives for the competitive candidates Mitterrand, Barre, and Chirac, for alternative sets of assumptions about how the candidates weighted electoral support in the first and second rounds of voting, and, for one-round elections, we have explored several alternative scenarios concerning the set of competing candidates. While we find that the candidate equilibria that we locate vary with the assumptions we employ, the central substantive finding that emerges from this exercise is that, to the extent that the candidates in a two-stage process attached at least moderate weight to the second round of voting - an assumption that strikes us as quite reasonable both one- and two-stage plurality contests would provide the candidates with incentives to moderate their positions. Therefore we conclude that the competitive candidates' policy incentives in the 1988 French presidential elections would have been similar, regardless of whether the selection process was conducted using the actual two-stage plurality system or an alternative one-stage system.

We note that our conclusion comes with the following caveats. First, although we find that the two-stage plurality system provided centripetal incentives to the competitive candidates Mitterrand, Barre, and Chirac, this two-stage system also allowed the extremist candidates Le Pen and Lajoinie to contest the election. Thus in 1988 the two-stage system allowed the French electorate to choose between a wide variety of viewpoints in the first round of voting, at the same time that it provided incentives for policy moderation from the competitive candidates. Second, our conclusions rely on the assumption that voters' decision rules would have been the same had they voted in a onestage election. Finally, we should be cautious about generalizing from the 1988 election to additional presidential elections.

The above caveats notwithstanding, our findings suggest that, in French presidential elections, competitive candidates' strategic policy incentives would not change significantly, were the presidential selection process changed to a one-stage plurality system.

\section{Notes}

1 A previous version of this paper was presented at the Conference on Pluralitarian and Majoritarian Systems, in Missilac France, June 20-23, 2004. 
2 We note, however, that there are additional spatial modeling studies that analyze two-stage plurality systems from a social choice perspective (see, e.g., Merrill, 1988). However, this research is not primarily concerned with candidates' policy strategies but instead with evaluating the efficiency or desirability of two-stage plurality systems (relative to other voting systems), that is, the extent to which alternative voting systems satisfy normative desirata such as selecting the Condorcet candidate (which is the candidate, who is majority-preferred to all rival candidates in a series of pairwise comparisons).

3 As discussed below, in French presidential elections the two top finishers in the first round advance to a runoff election held 2 weeks later. In district-level elections to the National Assembly, by contrast, all candidates who win at least $12.5 \%$ of the first-round vote are eligible to advance to the runoff election. For an interesting study of how the two-stage process affects parliamentary candidates' strategies in France, see Tsebelis (1990, chapter 7).

4 The 1988 French presidential election also featured four minor candidates, all of whom won less than $4 \%$ of the valid votes cast.

5 This assertion may appear questionable in the case of Le Pen, who finished within six percentage points of the second-place Chirac in the first round of voting. However, in earlier work on the 1988 presidential elections (Adams and Merrill, 2000), we report analyses suggesting that Le Pen's first-round vote would have fallen below Chirac's regardless of the policies that Le Pen presented. We also note that even had Le Pen advanced to the second round, he had no realistic chance of winning the runoff election, given the small number of voters who identified with the National Front, and the refusal of the mainstream right-wing parties to form an electoral alliance with the National Front.

6 Adams et al. (2004b) report empirical analyses of elections in eight Western European democracies (including France) suggesting that Communist and extreme nationalist parties do not adjust their policies in response to public opinion. These findings support our assumption that in the 1988 French presidential election Lajoinie and Le Pen - the candidates of the Communist and the National Front parties, respectively — were making expressive appeals rather than attempting to maximize their electoral support.

7 All of the substantive conclusions that we report below would be unchanged if we instead assumed that Barre and Chirac's focus in the first round was on maximizing their expected votes.

8 Intuitively, it appears plausible that Barre and Chirac placed greater emphasis upon the firstround vote than did Mitterrand, given that the latter was virtually assured of advancing to the second round. Alternative simulations in which we varied the weights that different candidates attached to the first and second rounds supported substantive conclusions that were similar to the ones we report below.

9 We also considered exploring candidate positioning under the assumption that candidates maximized their subjective probabilities of being elected, that is, that they maximized their subjective joint probabilities that they would advance to - and subsequently win - the runoff election. The difficulty with this approach is that it forces us to make strong (and unverifiable) assumptions about the candidates' beliefs about the uncertainty associated with each round of voting, and also about how the probabilities at each round were related to each other. For a study of these issues in one-round elections see Chapter 12 in Adams et al. (2005).

10 We thank an anonymous referee for stressing this point to us.

11 We note that in the parliamentary elections of 1997 the UDF and RPR's electoral strategy involved running a single 'unity' candidate at the first round in many districts, in order to avoid splitting the first-round vote so that this candidate would be sure of advancing to the second round. This strategy was motivated by the increased support for the far right National Front, which threatened to siphon off significant support from the center-right parties (see Givens, 2005). 
12 Expressive benefits are typically conceptualized as utilities that individuals or groups derive from taking some action, rather than as utilities that depend on the outcomes that result from the action (the latter are typically referred to a instrumental benefits). Scholars have invoked expressive benefits to explain why citizens turn out to vote, and these benefits have also been explored in the context of spatial models of party competition (see Roemer, 2001).

13 That is, we assumed that Mitterrand sought to maximize the difference between his expected vote and Barre's expected vote, while Barre similarly sought to maximize the difference between his expected vote and Mitterrand's expected vote.

14 Note that we have reversed the endpoints of the three policy scales so that the most left-wing response is 1 and the most right-wing response 7 . In addition, the survey did not record respondents' placements of Lajoinie on the three policy scales, so we report instead their placements of the Communist party.

15 We note that Lewis-Beck and Chlarson (2002) report similar substantive conclusions in their analyses of voting in the first and second rounds of the 1995 French presidential election, although their analyses suggest that party identification may be a more salient factor in the first round of voting.

16 This approach to estimating the electoral effects of candidate positioning has been widely used in recent years (see Alvarez and Nagler, 1995, 1998; Schofield et al., 1998; Adams and Merrill, 1999, 2000; Schofield and Sened, 2004).

17 Barre's expected margin vs Chirac equals the difference between Barre's expected vote and Chirac's expected vote, while Chirac's expected margin vs Barre is similarly defined.

18 We performed additional computations, which located a Nash equilibrium for the competitive candidates along the three policy scales (in addition to the Left-Right scale). The candidates' Left-Right equilibrium positions for this four-dimensional equilibrium were similar to the onedimensional equilibrium configurations that we report below.

19 We performed alternative computations in which we assumed that Mitterrand anticipated that his second-round opponent would be Barre, rather than Chirac. For this scenario, the computed equilibria were as follows (where $M, B$, and $C$ represent the equilibrium positions for Mitterrand, Barre, and Chirac, respectively): for $w_{1}=1$ (first-round emphasis): $M=3.09$, $B=4.69, C=4.93$; for $w_{1}=0.75, M=3.28, B=4.47, C=4.71$; for $w_{1}=0.5, M=3.48, B=4.26$, $C=4.47$; for $w_{1}=0.25, M=3.73, B=4.06, C=4.22$; for $w_{1}=0$ (second-round emphasis), $M=3.92, B=3.92, C=3.92$.

20 The major right-wing candidate's incentive to shift further to the right with Le Pen in the race is due to the fact that Le Pen's presence jeopardizes the mainstream right candidate's support from right-wing voters. Mitterrand's motivation to shift further to the left when Le Pen enters the race is because Le Pen's entrance further reduces Mitterrand's likelihood of attracting right-wing support - since these voters now have two right-wing alternatives to choose from, at least one of whom is virtually certain to be preferable to Mitterrand - so that Mitterrand attaches less weight to these voters' policy preferences, compared with the pure two-candidate elections scenario. We note that these types of strategic calculations are explored in depth in Merrill and Adams (2002).

21 The mixing parameter, $\beta$, has been used by Merrill and Grofman (1997) and Dow (1997) because of its ease of interpretation. With the factor 2 in the definition of utility, this equation implies that the indifference point between a pair of candidates moves linearly with $\beta$ between its respective positions for the two pure models. Thus a value of $\beta=0.5$ specifies an indifference point halfway between the two pure models.

22 As discussed in footnote ${ }^{21}$ above, the parameter $\beta$ in Eq. (A2) specifies the degree to which voters prefer candidates who propose policies that are more extreme than the voters' own beliefs. The value $\beta=0.5$, for instance, indicates that a voter who self-places at 5 along one of 
the 1-7 policy scales prefers a candidate located at 6 along the scale, while the value $\beta=0.75$ indicates that a voter who self-places at 5 prefers a candidate located at 5.33.

23 Substantively, Chapter 5 in Adams et al. (2005) presents arguments that French voters had reasons to discount the candidates' proposals in the run-up to the 1988 election, given the fact that Mitterrand - the incumbent president since 1981 - had reversed some of the key economic and social policies that had been implemented early in his first term, while Chirac - the incumbent premier since 1986 - had proved unable (or unwilling) to fully enact his conservative policy agenda, in part due to schisms within the right-wing majority in the National Assembly. Thus, the political events of 1981-1988 provided grounds for French voters to infer that the winner of the 1988 presidential election would face difficulties in fully implementing his policy agenda. Given this situation, it would be rational for outcome-oriented voters to support candidates proposing policies more extreme than the voters' sincere policy preferences, since voters would project that eventual government policy outputs would be more moderate versions of the winning candidate's pre-election promises.

Statistically, Chapter 5 in Adams et al. (2005) presents results that the difference in the loglikelihood between a mixed directional-proximity voting model and a standard proximity model is statistically significant at the 0.005 level, which strongly suggests that the mixed model is the appropriate one for the 1988 French Presidential election.

24 Merrill and Grofman (1997, 1999), Westholm (1997), and Dow (1997) have employed individual placements, while Rabinowitz and Macdonald and their co-authors use mean placement over all respondents. We performed alternative computations using voter-specific candidate placements, and found that these supported substantive conclusions that were identical to the ones we report below.

25 Two alternatives to the CL model are the Generalized Extreme Value Model (GEV) and Multinomial Probit (MNP), both of which relax the assumptions that the error terms are uncorrelated across candidates. Elsewhere (Adams and Merrill, 1998) we compare the candidates' strategies in the first round of the 1988 French presidential election using parameter estimates derived from the CL and the GEV models, and we find that the candidates' computed vote-maximizing positions were quite similar across models.

26 For each of the three dimensions other than Left-Right, we replaced respondents' missing candidate placements with the mean placement over all respondents. Because some respondents did not self-place on all four dimensions, the spatial model component of utility for each respondent was computed as the average of the utilities given in Eq. (A2) over the useable dimensions.

27 Note that we do not report estimates of candidate-specific intercepts in Table A1 (part a), because it is not feasible to estimate these parameters while simultaneously estimating the value of the mixing parameter $\beta$ in Eq. (A2), which specifies the relative contributions of directional vs proximity motivations to voters' evaluations of the candidates' policy positions (see Merrill and Grofman, 1999, Appendix 7.1; Adams et al., 2004a). We note, however, that the candidates' expected vote shares, as computed from the parameter estimates reported in Table 3, closely match the sample vote, thereby suggesting that the intercepts were approximately equal across candidates (see Table A1 (part b) below).

28 The class variable runs from -1 (self-described working class) to +1 (self-described middle class). The income variable runs from 1 (less than 5,000 francs per month) to 4 (over 15,000 francs per month). The sex variable is coded 0 for female, 1 for male.

29 Note that given our focus on the electoral effects of candidate policy positioning, it does not matter for our purposes whether this more complex model better captures the voter's decision process. This is because in the simulations reported below, the respondents' attributes - that is, their policy positions, partisanship, and sociodemographic characteristics — are held constant 
as the candidates' policies are varied. Hence, it does not matter, for our purposes, whether nonpolicy-related factors influence the vote via the partisan component or the sociodemographic component in the vote function; in either case they should have comparable effects upon the respondents' vote probabilities, which is what interest us here.

\section{References}

Adams, J., Benjamin, B. and Jay, D. (2004a) 'Representation in congressional campaigns: evidence for directional/discounting motivations in US senate elections', Journal of Politics 66(2): $348-373$.

Adams, J., Clark, M., Ezrow, L. and Glasgow, G. (2004b) 'Understanding change and stability in party ideologies: do parties respond to public opinion or to past election results?' British Journal of Political Science 34(4): 589-610.

Adams, J. and Merrill III, S. (1998) 'A Downsian model of candidate competition in the 1988 French presidential election', Annual Meeting of the Western Political Science Association; March 1998, Los Angeles.

Adams, J. and Merrill III, S. (1999) 'Modeling party strategies and policy representation in multiparty elections: why are parties so extreme?'American Journal of Political Science 43: 765-791.

Adams, J. and Merrill III, S. (2000) 'Spatial models of candidate competition and the 1988 French presidential election: are presidential candidates vote-maximizers?' Journal of Politics 62: 729-756.

Adams, J., Merrill III, S. and Grofman, B. (2005) A Unified Theory of Party Competition: A CrossNational Analysis Integrating Spatial and Behavioral Factors, Cambridge: Cambridge University Press.

Alvarez, M. and Nagler, J. (1995) 'Economics, issues, and the Perot candidacy: voter choice in the 1992 presidential election', American Journal of Political Science 39: 714-744.

Alvarez, M. and Nagler, J. (1998) 'When politics and models collide: estimating models of multiparty elections', American Journal of Political Science 42: 55-96.

Campbell, A., Converse, P.E., Miller, W.E. and Stokes, D.E. (1960) The American Voter, New York: Wiley.

Converse, P. and Pierce, R. (1993) 'Comment on Fleury and Lewis-Beck', Journal of Politics 55: $1110-1117$.

Dow, J. (1997) 'Voter choice and strategies in French presidential elections: the 1995 first ballot election', Annual Meeting of the Midwest Political Science Association, April 1997, Chicago.

Duverger, M. (1954) Political Parties, New York: Wiley.

Erikson, R. and Romero, D. (1990) 'Candidate equilibrium and the behavioral model of the vote', American Political Science Review 84: 1103-1126.

Fleury, C. and Lewis-Beck, M. (1993) 'Anchoring the French voter: ideology versus party', Journal of Politics 55: 1100-1109.

Givens, T. (2005) Voting Radical Right in Western Europe, Cambridge: Cambridge University Press.

Grofman, B. (1985) 'The neglected role of the status quo in models of issue voting', Journal of Politics 47: 230-237.

Huber, J. and Inglehart, R. (1995) 'Expert interpretations of party space and party locations in 42 societies', Party Politics 1: 73-111.

Iversen, T. (1994) 'Political leadership and representation in Western European democracies: a test of three models of voting', American Journal of Political Science 38: 45-74. 
Kedar, O. (2002) 'Balancing the seesaw: rationality and menu dependence in voter behavior', Presented at the Annual Meeting of the Midwest Political Science Association, Chicago IL, April 25-28.

Lacy, D. and Philip, P. (2001) 'Downsian voting and separation of powers in the 1998 Texas and Ohio gubernatorial elections', Presented at the Annual Meeting of the Midwest Political Science Association, Chicago IL, April 25-28.

Lewis-Beck, M. and Chlarson, K. (2002) 'Party, ideology, institutions, and the 1995 French presidential election', British Journal of Political Science 32: 489-512.

Merrill III, S. (1988) Making Multicandidate Elections More Democratic, Princeton, NJ: Princeton University Press.

Merrill III, S. and Adams, J. (2001) 'Computing Nash Equilibria in probabilistic, multiparty spatial models with nonpolicy components', Political Analysis 9: 347-361.

Merrill III, S. and Adams, J. (2002) 'Centrifugal incentives in multicandidate elections', Journal of Theoretical Politics 14: 275-300.

Merrill III, S. and Grofman, B. (1997) 'Directional and proximity models of voter utility and choice', Journal of Theoretical Politics 9: 25-48.

Merrill III, S. and Grofman, B. (1999) A Unified Theory of Voting: Directional and Proximity Spatial Models, Cambridge: Cambridge University Press.

Pierce, R. (1995) Choosing the Chief: Presidential Elections in France and the United States, Ann Arbor: University of Michigan Press.

Pierce, R. (1996) French Presidential Election Survey, 1988 [computer File]. ICPSR version. Ann Arbor, MI: Roy Pierce, University of Michigan [producer], 1995. Ann Arbor, MI: Inter-university Consortium for Political and Social Research, 1996.

Rabinowitz, G. and Macdonald, S.E. (1989) 'A directional theory of issue voting', American Political Science Review 89: 93-121.

Roemer, J. (2001) Political Competition: Theory and Applications, Cambridge, MA: Harvard University Press.

Rose, R. and McAllister, I. (1990) The Loyalties of Voters: A Lifetime Learning Model, Sage Publications: London.

Schofield, N., Martin, A., Quin, K. and Whitford, A. (1998) 'Multiparty competition in the Netherlands and Germany: a model based on multinomial probit', Public Choice 96: 257-293.

Schofield, N. and Sened, I. (2004) 'Multiparty Competition in Israel, 1992-96', Typescript.

Tsebelis, G. (1990) Nested Games: Rational Choice in Comparative Politics, Berkeley: University of California Press.

Westholm, A. (1997) 'Distance versus direction: the illusory defeat of proximity theory', American Political Science Review 91: 865-883.

\section{Appendix A. A Random Utility Voting Model for the First Round of the 1988 French Presidential Election}

The model we estimate for the first round of voting in the 1988 French presidential election views the voter $i$ 's utility for a candidate $K, U_{i}(K)$, as a function of: $V_{i K}$, the vector of $i$ 's utilities for $K$ 's policy and ideological positions; $t_{i}$, the vector of $i$ 's individual characteristics; and a random disturbance term $\mu_{i K}$ (whose distribution is given below)

$$
U_{i}(K)=A V_{i K}+B_{K} t_{i}+\mu_{i K}
$$

where $A$ and $B$ represent vectors of parameters to be estimated. 
With respect to the policy component $V_{i K}$, we specify a mixed directionalproximity metric, which incorporates elements from Rabinowitz and Macdonald's (1989) directional theory of policy voting along with the standard proximity voting model. We specify voter $i$ 's utility for candidate $K$ 's position along issue $j$ as

$$
V_{i j K}=2(1-\beta)\left(x_{i j}-N_{j}\right)\left(x_{K j}-N_{j}\right)-\beta\left(x_{i j}-x_{K j}\right)^{2}
$$

where $x_{i j}$ represents the voter's position, $x_{K j}$ her perception of $K$ 's position, and $N_{j}$ the neutral point along issue $j$ for the directional model relative to both direction and intensity (see Rabinowitz and Macdonald, 1989) which we locate at 4 along each dimension, the midpoint of the 1-7 scale. The mixing parameter $\beta$, which is to be empirically estimated, indicates the relative importance of proximity and directional motivations. ${ }^{21}$ When $\beta=0$, the proximity term drops out and we have the case of pure directional voting. When $\beta=1$, the directional component drops out and we have the standard proximity model. Values of $\beta$ between zero and one indicate that the voter has both directional and proximity motivations, in which case voters tend to prefer candidates who propose policies that are similar to, but more extreme than, the voters' own preferred policies (so that for instance center-left voters may prefer distinctly left-wing candidates). ${ }^{22}$ This taste for candidates who propose policies that are more extreme than the voters' own positions may arise either because voters prefer politicians who provide policy leadership on salient issues (Iversen, 1994), or, alternatively, because voters discount the candidates' abilities to fully implement their policy promises if they are elected (see Grofman, 1985; Merrill and Grofman, 1999; Lacy and Paolino, 2001; Kedar, 2002). The mixed directional-proximity metric given in Eq. (A2) has been empirically evaluated by Iversen (1994), Merrill and Grofman (1997, 1999), and Adams and Merrill (1998, 1999), each of whom conclude that this model explains voting behavior better than either pure model does by itself. Elsewhere (see Chapter 5 in Adams et al., 2005) we provide further justifications - both substantive and statistical - for this model in the context of voting in the 1988 French presidential election. ${ }^{23}$ Computation of model utilities was performed using respondents' mean candidate placements. ${ }^{24}$

With respect to $t_{i}$, the vector of individual voter characteristics, we included respondents' perceptions of national and personal economic conditions, sex (male or female), age, and sociodemographic characteristics relating to class and income. Also included was the respondent's partisanship, coded 1 if the respondent identified with the candidate's party and zero otherwise. Use of the party i.d. variable in voting research is controversial for elections held outside the United States, with some analysts arguing that respondents' reported partisanship is equivalent to their current vote intention (e.g., Rose 
and McAllister, 1990, 156). However, Converse and Pierce (1993; but see also Fleury and Lewis-Beck, 1993) present evidence that this is not the case in French elections, a conclusion supported by an analysis of the 1988 data, which shows that of the 565 respondents who reported voting for one of the major candidates in the 1988 election and who reported a party identification, $20 \%$ crossed party lines and voted for a candidate from a rival party. This is actually a higher defection rate than that reported for the 1988 American presidential election, for which ANES data shows that only $14 \%$ of respondents reported crossing party lines (Erikson and Romero, 1990). This supports the conclusion that partisanship should be viewed as an independent variable in the 1988 French election (see also Lewis-Beck and Chlarson, 2002).

The multivariate model we use to analyze voter choice is Conditional Logit (CL), in which the random disturbance terms $\mu_{i}$ are assumed to be distributed independently according to the extreme value distribution. ${ }^{25}$ The CL model expresses the probabilities of voting for each candidate as functions of the utilities for the candidates, which in turn are expressed in terms of both voter-specific variables and variables that relate voters to candidates.

\section{Parameter estimates for the $\mathrm{CL}$ vote model}

We estimated the parameters of our vote model for the subsample of 748 of the 1,013 respondents interviewed in Pierce's 1988 French Presidential Election Study (1996), who reported voting for one of the five major candidates at the first ballot, and who placed themselves and the five major candidates on the Left-Right scale. ${ }^{26}$ In order to simplify the subsequent simulations on candidate movement, parameter estimates that were not statistically different from zero in the initial analysis were set to zero, and the remaining parameters were recalculated on this basis. ${ }^{27}$

Table A1 (part a) displays the resulting parameter estimates for the vote model. Note that the parameters for partisanship and for each of the four policy dimensions are positive and statistically significant, which supports the conclusion that both policies and party identification influenced the vote. The estimated mixing parameter $\beta=0.66$ is statistically different from 0 and 1 at the 0.01 level, indicating that voters had mixtures of proximity and directional motivations. The parameter estimate $\beta=0.66$ implies that voters prefer candidates whose policy promises are about 50\% more extreme than the voter's preferred policy outcomes (relative to the center of the 1-7 scales), so that for instance a voter who self-places at 5.0 along the Left-Right scale prefers a candidate located at 5.5, and a voter who self-places at 3.0 prefers a candidate located at 2.5. As discussed above, voters' tastes for candidates who 
Table A1 (a) Logit equation predicting the first-round vote, 1988 French presidential election $(N=748)$ and (b) projected vote shares

\begin{tabular}{|c|c|c|c|c|c|}
\hline & Estimated parameter & & & & \\
\hline \multicolumn{6}{|l|}{ (a) Policy parameters } \\
\hline Left-Right & $0.179(0.023)$ & & & & \\
\hline Immigration & $0.028(0.011)$ & & & & \\
\hline Public sector & $0.051(0.013)$ & & & & \\
\hline Church schools & $0.029(0.015)$ & & & & \\
\hline Mixing parameter & $0.66(0.11)$ & & & & \\
\hline Party identification & $2.15(0.12)$ & & & & \\
\hline \multicolumn{6}{|l|}{ Sociodem. variables } \\
\hline Class (Chirac) & $0.32(0.14)$ & & & & \\
\hline Income (Lajoinie) & $0.28(0.16)$ & & & & \\
\hline Sex (Le Pen) & $0.23(0.16)$ & & & & \\
\hline \multirow[t]{2}{*}{ Log likelihood } & -597.4 & & & & \\
\hline & Lajoinie & Mitterrand & Barre & Chirac & Le Pen \\
\hline (b) Sample vote (\%) & $8.8 \%$ & $41.2 \%$ & $18.0 \%$ & $19.1 \%$ & $12.8 \%$ \\
\hline Projection from voting model & 12.3 & 37.6 & 18.4 & 22.0 & 9.6 \\
\hline
\end{tabular}

Note: The candidates' expected votes are computed using the coefficients reported in Table Al (part a), using the assumption that each candidate was located at his actual (perceived) position along the Left-Right and policy scales included in the model.

promise policies that are similar to, but more extreme than, the voters' preferred government policy outputs plausibly arises because voters anticipate that the winning presidential candidate will face obstacles to fully implementing his policy promises (see also footnote ${ }^{23}$ ).

The most striking empirical result is the scant effect of voters' sociodemographic characteristics and economic evaluations upon the vote. Of the variables examined (retrospective economic evaluations, income, class, age, and sex), only class, income, and sex were estimated to have statistically significant impacts, and these only with respect to three candidates: class for Chirac (with middle-class respondents most likely to support Chirac), income for Lajoinie (with evaluations declining with income), and sex for Le Pen (with males most likely to support Le Pen). ${ }^{28}$ (Note that since each sociodemographic parameter is estimated for only one candidate, we report the parameter estimates in a single column in Table 3). A plausible explanation is that sociodemographic variables indirectly effect the vote by influencing respondents' partisanship or their policy preferences, as posited in the 'funnel of 
causality' developed by the Michigan Model of voter choice (e.g., Campbell et al., 1960). ${ }^{29}$

The candidates' expected aggregate votes for the model are given in Table A1 (part b) (row 2), along with the distribution of the respondents' reported votes (row 1). The candidates' expected votes are calculated by summing the respondents' vote probabilities, so that the expected vote $\operatorname{EV}(K)$ for candidate $K$ is given as:

$$
\operatorname{EV}(K)=1 / n \sum_{i=1}^{n} P_{i}(K)
$$

where $P_{i}(K)$ represents the probability of the $i$ th individual voting for candidate $K$, and $n=748$ is the number of respondents included in the statistical analysis. Note that in these and all subsequent calculations, candidates' votes are expressed as percentages of the five-candidate vote, thereby eliminating from consideration the minor candidates who competed in the first round of voting. The projected aggregate vote is quite similar to the sample vote. 